\title{
A Polyaxonal Amacrine Cell Population in the Primate Retina
}

\author{
Martin Greschner, ${ }^{1,3}$ Greg D. Field, ${ }^{2,3}$ Peter H. Li, ${ }^{3}$ Max L. Schiff, ${ }^{3}$ Jeffrey L. Gauthier, ${ }^{3}$ Daniel Ahn, ${ }^{3}$ Alexander Sher, ${ }^{4}$ \\ Alan M. Litke, ${ }^{4^{*}}$ and E. J. Chichilnisky ${ }^{3,5^{*}}$ \\ ${ }^{1}$ Department of Neuroscience, University Oldenburg, 26111 Oldenburg, Germany, ${ }^{2}$ Department of Cell and Neurobiology, Zilkha Neurogenetic Institute, \\ Keck School of Medicine, University of Southern California, Los Angeles, California 90089, ${ }^{3}$ Systems Neurobiology Laboratories, Salk Institute for Biological \\ Studies, La Jolla, California 92037, ${ }^{4}$ Santa Cruz Institute for Particle Physics, University of California, Santa Cruz, Santa Cruz, California 95064, and \\ ${ }^{5}$ Department of Neurosurgery and Hansen Experimental Physics Laboratory, Stanford University, Stanford, California 94305
}

Amacrine cells are the most diverse and least understood cell class in the retina. Polyaxonal amacrine cells (PACs) are a unique subset identified by multiple long axonal processes. To explore their functional properties, populations of PACs were identified by their distinctive radially propagating spikes in large-scale high-density multielectrode recordings of isolated macaque retina. One group of PACs exhibited stereotyped functional properties and receptive field mosaic organization similar to that of parasol ganglion cells. These PACs had receptive fields coincident with their dendritic fields, but much larger axonal fields, and slow radial spike propagation. They also exhibited $\mathrm{ON}-\mathrm{OFF}$ light responses, transient response kinetics, sparse and coordinated firing during image transitions, receptive fields with antagonistic surrounds and fine spatial structure, nonlinear spatial summation, and strong homotypic neighbor electrical coupling. These findings reveal the functional organization and collective visual signaling by a distinctive, high-density amacrine cell population.

\section{Introduction}

The mammalian retina is characterized by exquisitely specific circuitry consisting of more than 60 morphologically and functionally distinct cell types that together mediate the first steps of visual processing (Rodieck, 1998; Masland, 2001; Gollisch and Meister, 2010). Among the major classes of retinal neurons, the amacrine cells are the most diverse and least understood. Anatomical studies indicate that at least 30 amacrine cell types, and likely more, can be distinguished by their morphology, connectivity to specific bipolar and ganglion cell types, and neurotransmitters (Masland, 2012). The diverse amacrine cell types are presumed to mediate a variety of visual functions. However, with a few exceptions, little is known about the visual response properties and functional organization of the many amacrine cell populations. As with the diverse interneuron assemblies in many neural circuits, understanding the properties of amacrine cell networks and signaling in the retina is essential to elucidating its function.

A distinctive subgroup of amacrine cells is the polyaxonal amacrine cells (PACs). These cells are characterized by axonal

\footnotetext{
Received Aug. 6, 2013; revised Jan. 10, 2014; accepted Jan. 28, 2014.

Author contributions: M.G., A.M.L., and E.J.C. designed research;M.G., G.D.F., P.H.L., M.L.S., J.L.G., D.A., A.S., and E.J.C. performed research; M.G., G.D.F., P.H.L., M.L.S., J.L.G., D.A., A.S., A.M.L., and E.J.C. analyzed data; M.G. and E.J.C. wrote the paper.

This work was supported by NIH Grant EY017992 (E.J.C.)., VolkswagenStiftung (M.G.), National Science Foundation (NSF) Postdoctoral Research Fellowship 1003198 (P.H.L.), BWF CASI (A.S.), the McKnight Foundation (A.M.L. and E.J.C.), and NSF Grant PHY-0750525 (A.M.L.). We thank the San Diego Supercomputer (enter and the NSF (Cooperative Agreements 05253071 and 0438741) for large-scale data storage. We also thank C.K. Hulse for technical assistance; M.I. Grivich, D. Petrusca, A. Grillo, P. Grybos, P. Hottowy, and S. Kachiguine for technical development; H. Fox, M. Taffe, E. Callaway, and K. Osborn for providing access to retinas; and S. Barry for machining.

The authors declare no competing financial interests.

${ }^{*}$ A.M.L. and E.J.C. contributed equally to this work.

Correspondence should be addressed to Martin Greschner, Department of Neuroscience, University of Oldenburg, 26111 Oldenburg, Germany. E-mail: martin.greschner@uni-oldenburg.de.

DOI:10.1523/JNEUROSCI.3359-13.2014

Copyright $\odot 2014$ the authors $\quad 0270-6474 / 14 / 343597-10 \$ 15.00 / 0$
}

processes that extend radially several millimeters from the tips of their dendrites (Dacey, 1988, 1989; Vaney et al., 1988; Mariani, 1990; Famiglietti, 1992; Freed et al., 1996; Taylor, 1996; Völgyi et al., 2001; Olveczky et al., 2003; Wright and Vaney, 2004; Davenport et al., 2007). The axons of PACs are located in the inner plexiform layer, providing opportunities to contact processes of other retinal interneurons as well as ganglion cells, which send visual information to the brain. Furthermore, the distinctive morphology of PACs suggests that they participate in modulating retinal signals over large areas of the visual field. In some cases, specific visual processing functions can be ascribed to PACs, for example, the suppression of spurious retinal signals introduced by eye movements in salamander and rabbit retinas (Olveczky et al., 2003; Baccus et al., 2008). Based on the current understanding of retinal circuitry, a natural hypothesis emerges that, as with retinal ganglion cells (RGCs), each distinct type of PAC forms a complete representation of visual space (Wässle et al., 1981), with distinctive and homogeneous stimulus selectivity (Devries and Baylor, 1997; Field and Chichilnisky, 2007), and network interactions (Mastronarde, 1983a,b; Greschner et al., 2011) that modulate visual signals sent to the brain. However, a systematic view of PAC function has not yet emerged because of the difficulty of characterizing the individual properties and collective organization of PACs, particularly in the primate retina.

Large-scale, high-density, multielectrode recordings present an opportunity to understand the collective organization and function of PAC populations, based on an electrical imaging approach (Litke et al., 2004; Petrusca et al., 2007). Applying this approach to isolated primate retinas, we describe a class of spiking neurons, which, unlike ganglion cells, exhibit action potential propagation simultaneously in many directions, unambiguously identifying them as PACs. Characterization of complete populations of these PACs revealed their homogeneous signaling 


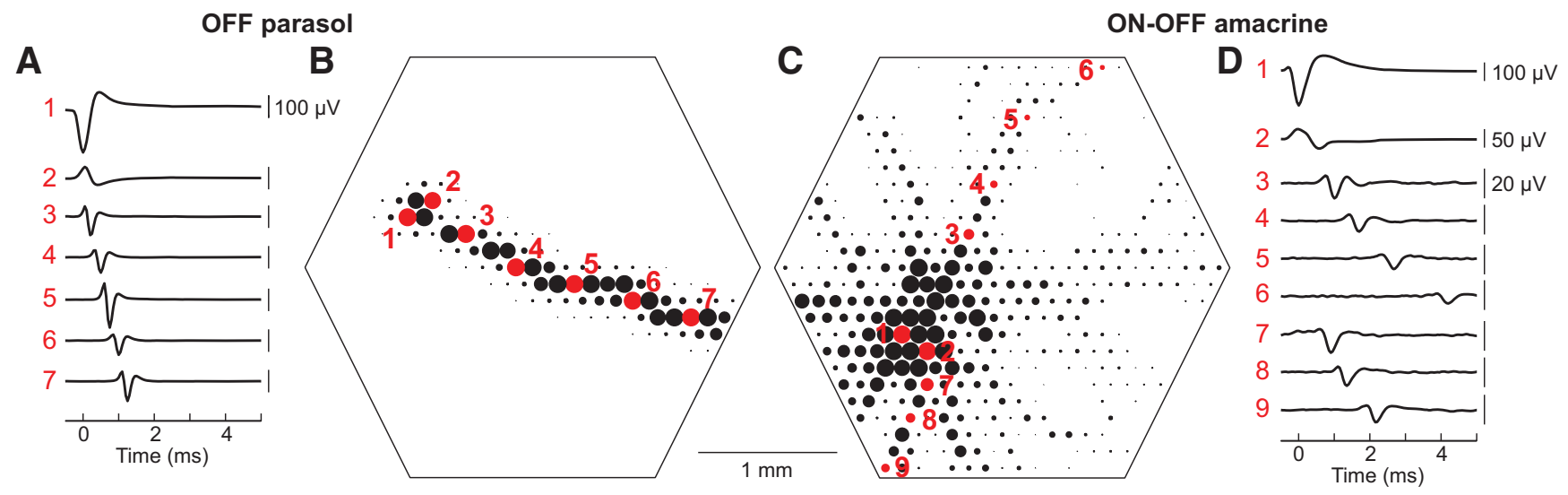

Figure 1. Electrical images of an OFF parasol RGC and ON-OFF PAC. The electrical image is the average spatiotemporal spike waveform recorded across the electrode array during the spikes detected from a specific cell. $\boldsymbol{A}, \boldsymbol{B}$, Electrical image of an $0 \mathrm{FF}$ parasol cell. Large somatic spikes were detected at the main electrode (1), opposite-sign dendritic spikes were detected nearby (2), and triphasic axon spikes were detected propagating across the array (3-7). Diameters of black and red circles represent the amplitude of the electrical image at each electrode that exhibited a voltage deflection greater than an arbitrary threshold (the large amplitudes displayed are saturated to avoid overlap). For all RGCs recorded, the axon spikes propagated in approximately the same direction (data not shown). C, D, Electrical image of a simultaneously recorded ON-OFF PAC. The large somatic spike (1) was accompanied by dendritic spikes nearby (2) and by axonal spikes propagating simultaneously in multiple directions away from the soma (3-10), unlike the single axon of the parasol cell.

properties and mosaic organization. This PAC type exhibited distinctive nonlinear and coordinated light response properties and strong homotypic electrical coupling, distinctive features that offer clues to its function in visual processing.

\section{Materials and Methods}

Electrophysiology. Retinas were obtained and recorded as described previously (Chichilnisky and Baylor, 1999; Field et al., 2007). Briefly, eyes were taken from terminally anesthetized macaque monkeys (Macaca mulatta, Macaca fascicularis) of either sex, used by other laboratories in the course of their experiments, in accordance with Salk Institute Institutional Animal Care and Use Committee guidelines for the care and use of animals. Immediately after enucleation, the anterior portion of the eye and the vitreous were removed in room light. Segments of peripheral retina $(6-14 \mathrm{~mm}$ temporal equivalent eccentricity) that were well attached to the pigment epithelium were dissected, isolated from the pigment epithelium, and placed flat, RGC side down, on a planar array of extracellular microelectrodes. Two different electrode arrays equipped with custom-designed integrated circuits were used. One array consisted of 512 electrodes with 60 $\mu \mathrm{m}$ spacing, covering a rectangular region $1890 \times 900 \mu \mathrm{m}$ (Litke et al., 2004). The second array consisted of 519 electrodes with $120 \mu \mathrm{m}$ spacing, covering a hexagonal region $3120 \mu \mathrm{m}$ wide. While recording, the retina was perfused with Ames' solution $\left(33-36^{\circ} \mathrm{C}\right)$ bubbled with $95 \% \mathrm{O}_{2}$ and $5 \% \mathrm{CO}_{2}, \mathrm{pH}$ 7.4.

Recordings were analyzed off-line to isolate the spikes of different cells, as described previously (Litke et al., 2004; Field et al., 2007). Briefly, candidate spike events were detected using a threshold on each electrode, and the voltage waveforms on the electrode and neighboring electrodes around the time of the spike were extracted. Clusters of similar spike waveforms were identified as candidate neurons if they exhibited a refractory period. Duplicate recordings of the same cell were identified by temporal cross-correlation and removed.
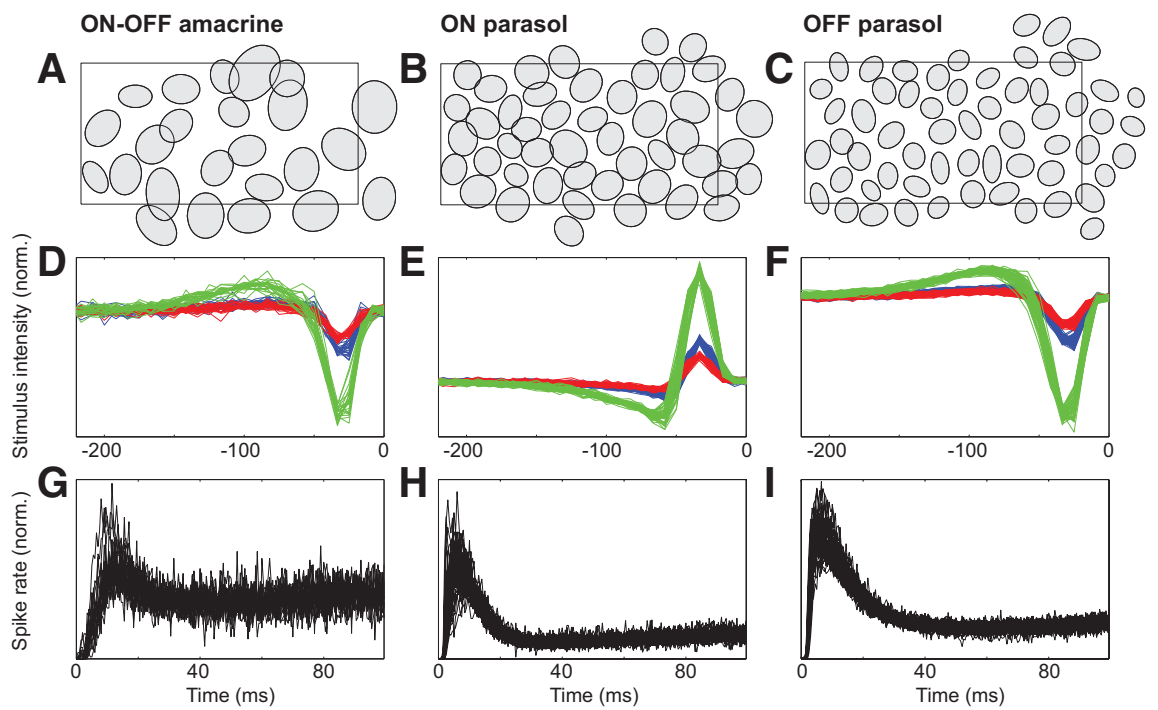

Figure 2. Functional organization of ON-OFF PACS, ON parasol and OFF parasol cells. $A-C$, Reverse correlation of spike trains of each cell with a white noise stimulus revealed the spatial receptive field of each cell (see Materials and Methods). Gaussian fits to receptive fields of recorded cells are shown as ellipses, accumulated for each cell type separately, and superimposed on the outline of the 512 -electrode array $(1890 \times 900 \mu \mathrm{m})$. The receptive fields of each cell type formed a regular mosaic tiling the region of retina recorded. $\boldsymbol{D}-\boldsymbol{F}$, Time course of reverse correlation at the receptive field center is shown for all cells of each type superimposed, and for each of the three display primaries (red, green, and blue). These time courses reveal biphasic integration over time before spike (i.e., biphasic impulse responses). G-I, Autocorrelation of spike trains of different cell types were obtained during white noise stimulation, and are shown superimposed for all cells of each type. Each trace shows, for one cell, the normalized spike rate as a function of time after the occurrence of a spike. The characteristic waveforms for cells of each type reveal homogeneous spike train dynamics (Devries and Baylor, 1997).

Electrical image. PACs were identified using electrical images (Litke et al., 2004). After spikes from different cells were segregated (see above), the spike-triggered average spatiotemporal electrical signal was calculated for each cell separately. Specifically, for each electrode, the voltage waveform during the time period from $0.5 \mathrm{~ms}$ before to several milliseconds after each spike from the cell was identified, and the average of all these waveforms was computed. This yielded an average voltage waveform on every electrode of the array. These waveforms were inspected for evidence of somatic, dendritic, and axonal kinetic signatures. To construct the electrical image, the absolute peak amplitude of the waveform at each electrode was displayed in the spatial layout of the array. The plot of the absolute peak amplitude was thresholded and saturated to improve visibility. In most recorded cells, the spikes propagated rapidly in one direction, the same direc- 
A

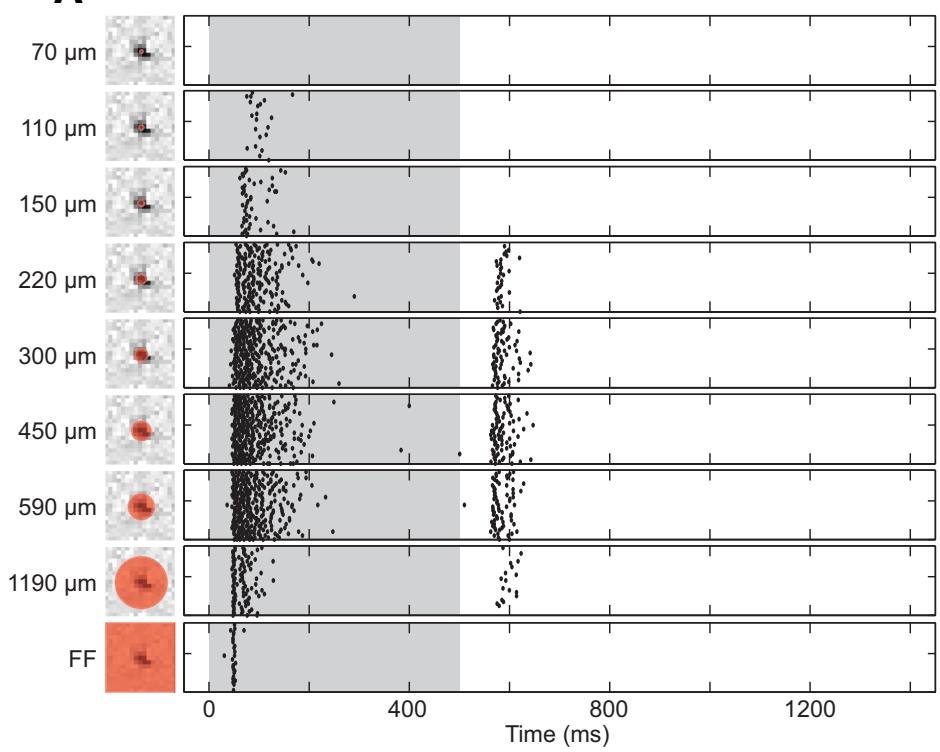

B

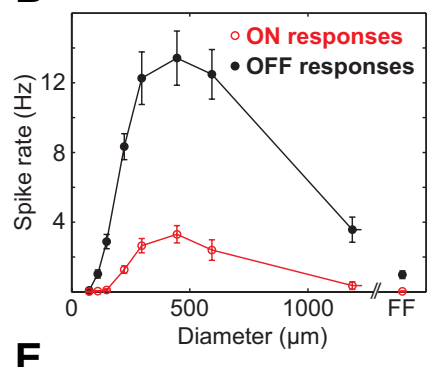

E

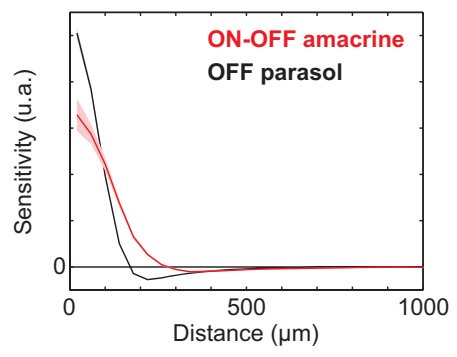

C ON-OFF amacrine

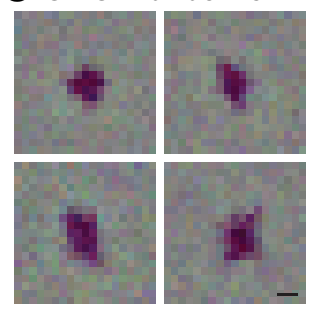

D off parasol

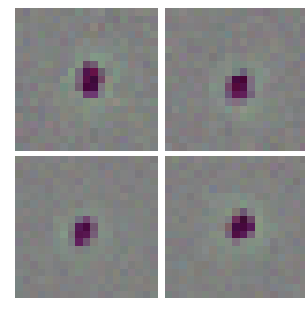

Figure 3. $0 \mathrm{~N}-0 \mathrm{FF}$ light responses and receptive field surrounds in PACs. $A$, Decrements of light $(0.0-0.5 \mathrm{~s}, 48 \%$ contrast) were delivered 35 times to the receptive field center (left panels) and responses recorded for $1.5 \mathrm{~s}$. Steps were delivered to regions of increasing size relative to the receptive field (red circles). Each panel on the right shows a raster of responses to repeated stimulation: each tick indicates the time of a spike, and data from repeated presentations are shown in separate rows. Strong responses following light decrement (time 0 ) were accompanied by variable-strength responses at light increment (time $0.5 \mathrm{~s}$ ). Size of a spot is given as the diameter. FF, Full-field stimulation. $\boldsymbol{B}$, Area-response function for four $0 \mathrm{~N}-0 \mathrm{FF}$ PACs in one recording, showing the mean spike count ( \pm 1 SEM) for dark spots of increasing diameter, as in $A$. OFF response (closed dots, $0-0.5 \mathrm{~s}$ ) and ON response (open circles, $0.5-1 \mathrm{~s}$ ) are shown separately. $\boldsymbol{C}$, Receptive fields of four $0 \mathrm{~N}-0 \mathrm{FF}$ amacrine cells, obtained by reverse correlation with white noise (see Materials and Methods) are shown, with each image centered on the receptive field of the cell. The strong dark region, indicating a dominant $0 \mathrm{FF}$ response, was surrounded by weaker light regions, indicating an antagonistic receptive field surround. Scale bar, $200 \mu \mathrm{m}$. D, Same as C, for four OFF parasol cells. The surround is similar but more easily discerned. $\boldsymbol{E}$, Cross-sectional profile of receptive fields in data from C and $\boldsymbol{D}$ for 29 ON-0FF PACs and 249 OFF parasol cells in one recording. Shaded area represents \pm 1 SEM.

tion for all cells in the recording (Fig. 1B). These were interpreted as representing spikes from RGCs propagating in the direction of the optic disc, which was always far (several millimeters) from the recording region. In a subset of cells, however, spikes were observed propagating in several directions simultaneously (Fig. 1C). These were interpreted as representing spikes from PACs, the only known neurons in the retina with multiple axons propagating over several millimeters.

Light stimulation. A white noise stimulus, composed of a lattice of square pixels updating randomly and independently of one another over time, was used to characterize the spatial, temporal, and chromatic response properties of recorded cells (Chichilnisky, 2001). The intensity of each display primary at each pixel location was chosen independently of the other primaries from a binary distribution at each refresh. The contrast of each primary (difference between the maximum and minimum intensities divided by the sum) was $96 \%$. The spike-triggered average (STA) stimulus obtained in response to white noise was taken as a summary of the spatiotemporal-chromatic light response properties of the cell (Chichilnisky, 2001).

Analysis. For cell-type classification, receptive fields (RFs) were summarized by fitting the STA with a parametric model (Chichilnisky and Kalmar, 2002; Field et al., 2007). The model consisted of the product of the following three functions: spatial, temporal, and chromatic. The temporal function was a difference of low-pass filters. The spatial function was a two-dimensional elliptical Gaussian function. The chromatic function consisted of two scalars representing the relative sensitivity to the three display primaries. These RF fits were visualized by an ellipse for each cell representing the $1 \mathrm{SD}$ contour of the Gaussian (Fig. 2A-C). Possible biases in the size of Gaussian fits associated with the fine RF structure of PACs compared with parasol cells (see Fig. 7) were not explored. Parameters of these fits (e.g., RF radius) were used in cell-type classification. Correspondences between functionally defined RGC types and the morphologically distinct RGC types, such as ON and OFF parasol cells (Fig. 2), were inferred based on cell densities and light response properties, as described previously (Field et al., 2007).

The spatial component of the STA was extracted by computing, for each spatial location, the inner product of the time course at that location with the mean time course over the strongest pixels. The strongest pixels were those with peak intensities $>2$ robust SDs from the mean. The multiple, superimposed RFs in Figure $7 C$ were spatially smoothed by convolution with a Gaussian with a width on the order of a pixel, and then thresholded. Thresholding consisted of defining a spatially contiguous region including the peak in which the pixel intensity was $>2$ SDs of the noise, and then setting to zero the intensities at other locations. Noise was estimated using values of the STA far outside the RF.

Responses to steps of light (Fig. 3A) were obtained using spots centered on the RF. PACs were first identified in a 15 min recording with a white noise stimulus, as described above. Spike sorting, electrical image and RF calculation, and cell-type identification were all performed online, and were completed $\sim 15 \mathrm{~min}$ after the end of the recording. This information was then used to present spots of various sizes centered on the RF of selected PACs.

Reversing gratings were sinusoidal spatial patterns with contrasts modulated in time at $4 \mathrm{~Hz}$. Ten spatial frequencies ranging from 0.2 to 28.7 cycles $/ \mathrm{mm}$ and eight spatial phases were used. The maximum value of F1 (fundamental component of response) and the mean value of F2 (second harmonic component) over all spatial phases was used to summarize the data (Hochstein, 1976). The contrast modulation was $96 \%$.

Cross-correlation functions (see Fig. $5 \mathrm{~A}, \mathrm{C}$ ) were obtained by binning spikes into $0.5 \mathrm{~ms}$ time bins and computing the correlation coefficient between the resulting spike count vectors, as a function of temporal offset. Each cross-correlation function was obtained by averaging over identical repeats of a random checkerboard stimulus, and the shuffled cross-correlation function (shift predictor) was subtracted to remove stimulus-driven correlations (Perkel et al., 1967). To summarize correlation strength over distance (see Fig. $5 B, D$ ), spikes were accumulated in $10 \mathrm{~ms}$ bins, and the correlation coefficient at zero offset was computed.

Images of natural scenes were selected from a monochrome natural image database (van Hateren and van der Schaaf, 1998) and assembled into a stimulus movie, as follows. Each image was presented for $1 \mathrm{~s}$, drifting in two dimensions according to the trajectory of eye movement traces recorded from a trained awake macaque monkey fixating a target in an unrelated task (Z. M. Hafed and R. J. Krauzlis, personal communi- 

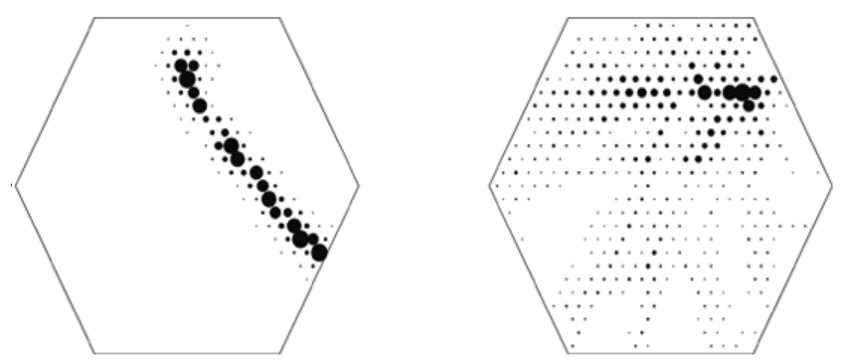

Movie 1. Animated electrical images of parasol retinal ganglion cell and ON-OFF polyaxonal amacrine cell as in Figure 1. Interval from $1 \mathrm{~ms}$ before the spike until $7 \mathrm{~ms}$ after. Frame duration is $0.05 \mathrm{~ms}$.

cation). Between images, an artificial saccade was generated, replacing the image by panning in $83 \mathrm{~ms}$. The relative response latency between ON-OFF PACs and OFF parasols was estimated based on the delay that produced the maximal correlation between their shifted response histograms.

\section{Results}

To examine the function of PACs, large-scale, high-density, multielectrode array recordings were performed in isolated macaque retinas. In addition to RGCs, these recordings revealed cells with unique, radial spike propagation over distances of several millimeters, which unambiguously identified them as PACs. The functional organization and physiology of these cells was then explored, revealing a homogeneous population with unusual properties.

\section{Functional identification of a polyaxonal amacrine cell type} To identify PACs and distinguish them from simultaneously recorded RGCs, the electrical image of the recorded cells was used (Litke et al., 2004; Petrusca et al., 2007). First, spikes from distinct recorded cells of all types were segregated from one another according to the temporal waveform of their action potentials recorded on electrodes near the soma, using standard methods (Litke et al., 2004; Frechette et al., 2005; see Materials and Methods). Then, the spikes from each cell were used to obtain a summary of the voltage deflections they induced across the entire electrode array, including electrodes distant from the soma. Specifically, using all the spike times of a given cell, the average voltage circa the time of the spike was calculated for every electrode in the array. This electrical image thus revealed the average spatiotemporal pattern of voltage deflections recorded during and after the occurrence of a spike, in each cell separately. The averaging procedure made it possible to detect and characterize small voltage deflections induced far from the soma.

The electrical image associated with an RGC (Fig. 1A, $B$; Movie 1) exhibited properties common to many spiking neurons: a large biphasic apparently somatic spike recorded on the primary electrodes, surrounded by smaller opposite-sign dendritic spikes on nearby electrodes, and followed by triphasic axonal spikes propagating in the direction of the optic disk. In contrast, the electrical image of PACs (Fig. 1C,D; Movie 1) revealed axonal spikes propagating outward from the soma simultaneously in multiple directions for several millimeters (Petrusca et al., 2007). These radially propagating axonal spikes were interpreted as an unambiguous signature of PACs.

\section{Functional organization and light responses}

PACs displayed a collective functional organization broadly similar to that of RGCs. The light responses of all recorded RGCs and
PACs were characterized simultaneously by computing the STA stimulus with a spatiotemporal white noise stimulus (Chichilnisky, 2001; Materials and Methods). From the STA, several distinguishing features of light response were identified, including the spatial receptive field size and the average response time course of each cell. These properties were used to distinguish the major RGC types, including ON and OFF parasol cells, which form $\sim 20 \%$ of the retinal signal and provide dominant visual input to the magnocellular layers of the LGN. The spatial receptive fields of each RGC type thus identified formed a regular mosaic covering the region of retina recorded (Fig. 2 B, C; Devries and Baylor, 1997; Chichilnisky and Kalmar, 2002; Frechette et al., 2005; Field et al., 2007). The same classification approach also revealed a functionally distinct group of PACs, identified by their radially propagating axons (Petrusca et al., 2007; Fig. 1). As with each RGC type, the receptive fields of this group of cells apparently formed a mosaic (Fig. 2A). Gaps in the mosaic likely reflect incomplete recording of the population, as seen with some RGC types (Field et al., 2007). The receptive fields of PACs were slightly larger than those of simultaneously recorded OFF parasol cells (mean \pm SEM, $116 \pm 7 \%$ in radius; $n=10$; Fig. $3 E$ ). The time course of the STA exhibited a dominant negative lobe, similar to that observed in OFF parasol cells (Fig. 2D,F). The relative strengths of the red, green, and blue primaries were similar in all three cell types, in a ratio consistent with dominant input from the $\mathrm{L}$ and $\mathrm{M}$ cones (Field et al., 2007). The kinetics of light response were similar to parasol cell kinetics (Fig. 2D-F), and more transient than midget cell kinetics (Field et al., 2007). The same was true for the spike autocorrelation functions (Fig. 2G-I), a distinguishing feature of different RGC types in the retina (Devries and Baylor, 1997; Field et al., 2007). The homogeneous functional properties and apparent mosaic organization of this group of PACs were taken as evidence that they constitute a morphologically and functionally distinct cell type.

In response to steps of light, these PACs exhibited ON-OFF light response characteristics similar to those previously described for PACs in the retinas of primates (Stafford and Dacey, 1997; Davenport et al., 2007). Stimulation with spots of light centered on the receptive field elicited brisk bursts of action potentials at light onset and offset (Fig. 3A). Therefore, these cells will be referred to henceforth as ON-OFF PACs. However, the OFF response was generally stronger than the ON response, particularly for stimuli that were small or large compared with the receptive field center (see below). This observation is consistent with the net OFF response revealed by the STA (Fig. 2D; see Discussion).

The ON-OFF PACs exhibited center-surround receptive field organization (Völgyi et al., 2001; Davenport et al., 2007). This was revealed by the reduced response strength to large stimuli (Fig. $3 B$ ) and can be also seen by the weak bright region surrounding the dark central region in their STAs (Fig. $3 C$ ). The surround was less regular than, but otherwise similar to, the surround observed in simultaneously recorded OFF parasol cells (Fig. 3D).

The receptive field center of each ON-OFF PAC was approximately spatially coincident with its soma and dendritic field, identified from the electrical image (Völgyi et al., 2001; Davenport et al., 2007). Specifically, the center of the receptive field coincided with a region of large amplitude somatic and dendritic spikes near the center of the electrical image, while the discrete radially propagating axons extended much farther (Fig. 4). This finding is consistent with the idea that the dendritic arbors (rather than the axons) of PACs are the main collectors of inputs 

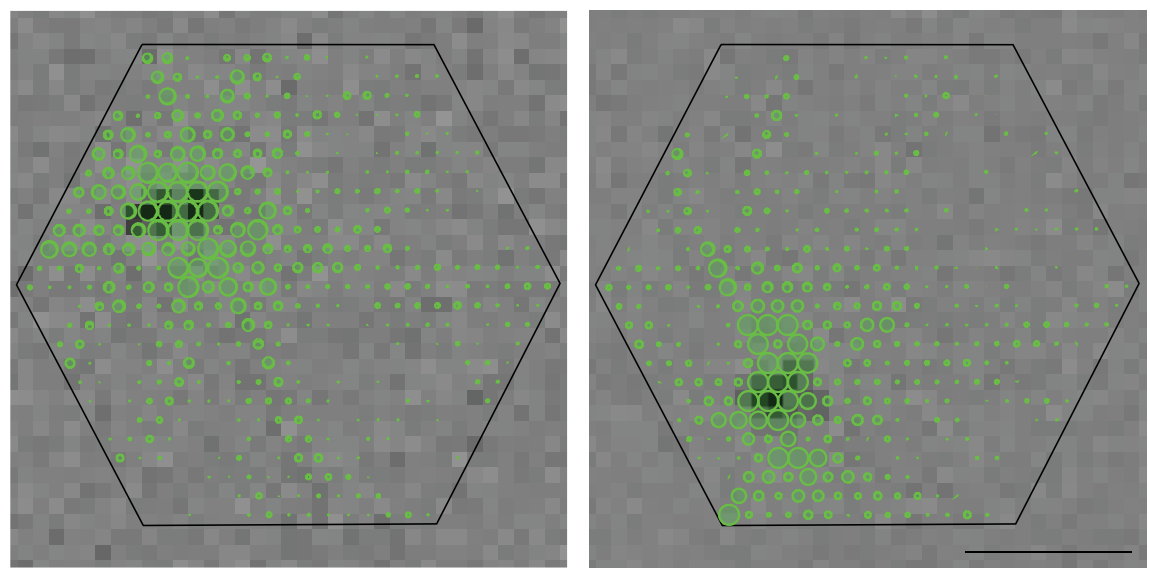

Figure 4. Relationship of receptive fields to dendritic and axonal fields of PACs. Electrical images (green) are shown for two cells, superimposed on the hexagonal outline of the electrode array (Fig. 1). In the electrical image of each cell, long radiating processes are evident and distinct from the dense central region of somatic and dendritic spikes. Receptive fields obtained by reverse correlation with white noise are shown as grayscale images in the background, with the dark central region coinciding with the region of recorded somatic and dendritic spikes in the electrical image. Scale bar, $1 \mathrm{~mm}$.
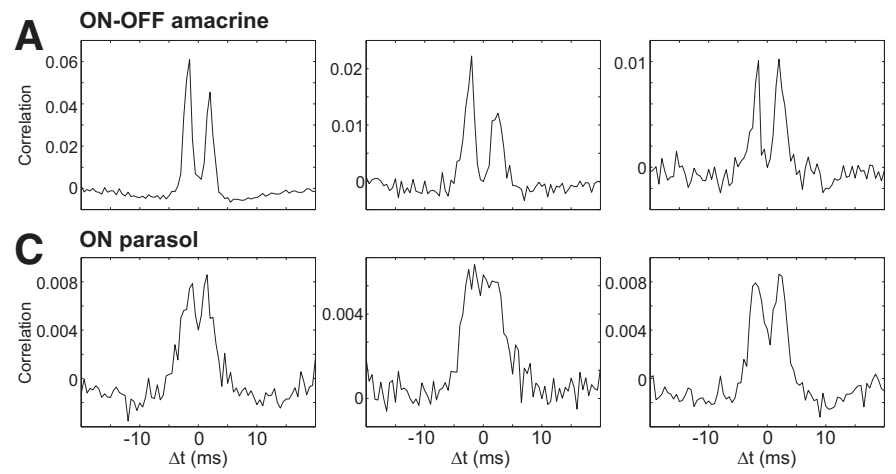

Figure 5. Homotypic cross-correlation in the firing of PACs and parasol cells. $A$, Cross-correlations are shown for three pairs of PACs in a single recording. Each panel shows the correlation coefficient of firing, proportional to the probability of one cell firing a spike as a function of time relative to the occurrence of a spike in a second cell. Each pair of cells exhibited two-peaked crosscorrelations suggestive of electrical coupling. Shuffled cross-correlation function was subtracted to correct for the stimulus-driven component of correlations. $\boldsymbol{B}$, The strength of a correlation is shown as a function of distance between the receptive field centers of recorded PACs in units of the mean receptive field radius (SD of Gaussian fit; see Materials and Methods). $\boldsymbol{C}, \boldsymbol{D}$, Same as $\boldsymbol{A}$ and $\boldsymbol{B}$, but for simultaneously recorded $\mathrm{ON}$ parasol cells.

from retinal interneurons. As a consequence, the outputs of each ON-OFF PAC extend over a much larger area than the lightdriven inputs.

\section{Electrical properties: homotypic coupling and spike propagation}

ON-OFF PACs exhibited strong, regular homotypic coupling. This was determined by examination of the cross-correlation in the spiking activity of immediate neighbors in the ON-OFF PAC mosaic. The cross-correlation indicates the probability of one cell firing a spike as a function of time relative to the firing of another cell. The cross-correlation between ON-OFF PACs typically exhibited two sharp peaks displaced from the origin (Fig. 5A), indicating that one cell in the pair tended to fire shortly before or after the other. This coupling was suggestive of reciprocal excitation mediated by gap junctions. Specifically, the peaks resembled those in the cross-correlation of neighboring ON parasol cells (Fig. 5C; Shlens et al., 2008; Trong and Rieke, 2008), which are known to be reciprocally electrically coupled (Trong and Rieke, 2008), presumably through intermediate amacrine cells (Dacey and Brace, 1992). However, the cross-correlation between ON-OFF
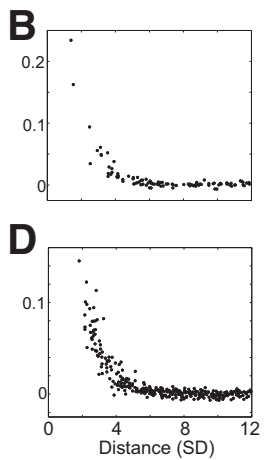

PACs was much stronger than between ON parasol cells, indicating a highly coupled network.

The strength of coupling between ONOFF PACs declined systematically with distance (Fig. 5B), similar to homotypic cross-correlations that have been observed in various RGC types in several species (Mastronarde, 1983a,b; Greschner et al., 2011) and similar to the correlations observed in simultaneously recorded $\mathrm{ON}$ parasol cells (Fig. 5D; Greschner et al., 2011). The observed coupling spread laterally beyond immediate neighbors in the mosaic, similar to coupling between $\mathrm{ON}$ parasol cells but unlike that in OFF parasol cells (Shlens et al., 2006; Greschner et al., 2011). This finding is consistent with different origins of coupling: reciprocal electrical coupling between ON-OFF PACs and between ON parasol cells (Dacey and Brace, 1992; Trong and Rieke, 2008) should propagate to non-neighbors in the mosaic, whereas shared inputs from photoreceptors in OFF parasol cells (AlaLaurila et al., 2011) should not. The strongest coupling was restricted to a radius similar to the receptive field radius (and thus dendritic field radius; Fig. 4). This suggests that coupling occurs primarily on the dendrites rather than on farreaching axons. The stereotyped form and spatial scale of the cross-correlation, and its distance dependence, further supported the identity of the ON-OFF PACs as a single morphological and functional cell type.

Positive correlations between $\mathrm{ON}$ OFF PACs and nearby OFF parasol and OFF midget cells, and negative correlations with nearby $\mathrm{ON}$ parasol and $\mathrm{ON}$ midget cells, were approximately consistent with their overlapping receptive fields (data not shown; AlaLaurila et al., 2011; Greschner et al., 2011). No strong longerrange correlations between ON-OFF PACs and midget and parasol cells near their axons were observed.

Action potential propagation in ON-OFF PACs was $\sim 0.5 \mathrm{~m} / \mathrm{s}$, approximately three times slower than in simultaneously recorded parasol cells (Fig. 6A,B). Propagation times were determined by identification of the average spike time at different locations in the electrical image (Fig. 1A,D). Given that ON-OFF PACs routinely exhibited axonal fields extending $>3 \mathrm{~mm}$ from the soma (Fig. $1 C$ ), a spike in an ON-OFF PAC requires 5-10 ms to propagate from the soma to the end of the axon. This propagation time places limits on how rapidly ON-OFF PACs could be expected to modulate visual signals by inhibiting activity in distant RGCs (see Discussion). Also, unlike in parasol cells (Fig. 6A,C), action potential propagation speed in ON-OFF PACs declined as a function of distance from the soma (Fig. 6A,D). This decline presumably reflects changes in factors controlling action potential propagation, such as diameter, leak currents, and sodium channel distribution, from the proximal to the distal axons. 
Nonlinearity, response dynamics, and receptive field microstructure

Although the overall structure of $\mathrm{ON}$ OFF PAC receptive fields resembled those of parasol cells (Fig. 2), their microstructure was strikingly different. The receptive field of each ON-OFF PAC exhibited several radial "flares," emanating from a central region of high sensitivity (Fig. 7A). These produced a less circularly symmetric sensitivity profile than that of simultaneously recorded parasol cells (Fig. $7 B$ ). This receptive field microstructure could result from the dendritic processes of $\mathrm{ON}$ OFF PACs, or from electrical coupling to neighboring cells (DeVries, 1999). In some cases, the microstructure of adjacent ON-OFF PAC receptive fields appeared to interdigitate (Fig. $7 C$ ), as has been observed previously in the more subtle microstructure of parasol and midget RGCs (Gauthier et al., 2009). This observation further supports the idea that the ON-OFF PACs form a spatially coordinated mosaic, and suggests that the flares primarily reflect the structure of the dendritic field.

ON-OFF PACs also differed from parasol cells in that their responses to sinusoidal gratings revealed a tuning to spatial frequencies higher than that of OFF parasol cells (Fig. 8A,B), despite the fact that ON-OFF PACs had slightly larger receptive fields (Fig. 2). A possible explanation for this finding is that the responses of ON-OFF PACs include a strong contribution from small nonlinear subunits within the receptive field that are rectified before summation, as has been observed in various RGC types in different species (Shapley and Victor, 1979; Demb et al., 2001). Consistent with this possibility, the component of response at twice the grating temporal modulation frequency (i.e., the F2) was greater than the component at the F1, for gratings of high spatial frequency (Fig. $8 \mathrm{C}$ ), indeed to a greater degree than in simultaneously recorded OFF parasol cells (Fig. 8D; Petrusca et al., 2007; Crook et al., 2008). Note, however, that the combination of an ON-OFF light response (Fig. 3) and apparent nonlinear subunits within the PAC receptive field limits the conclusions that can be drawn about the mechanisms of light response from such

measurements.

The strongly nonlinear spatial integration in ON-OFF PACs suggests that their responses to structured visual stimuli could differ markedly from the responses of RGCs such as parasol cells. As a simple test of this possibility, images of natural scenes were moved over the retina according to a measured trajectory of saccadic and fixational eye movements in macaque monkeys (see Materials and Methods). OFF parasol cells exhibited dense patterns of firing throughout the presentation of these stimuli, with sharply coincident increases or decreases in firing after rapid image shifts, and different firing patterns in different cells, reflecting their different spatial podistance from the soma.
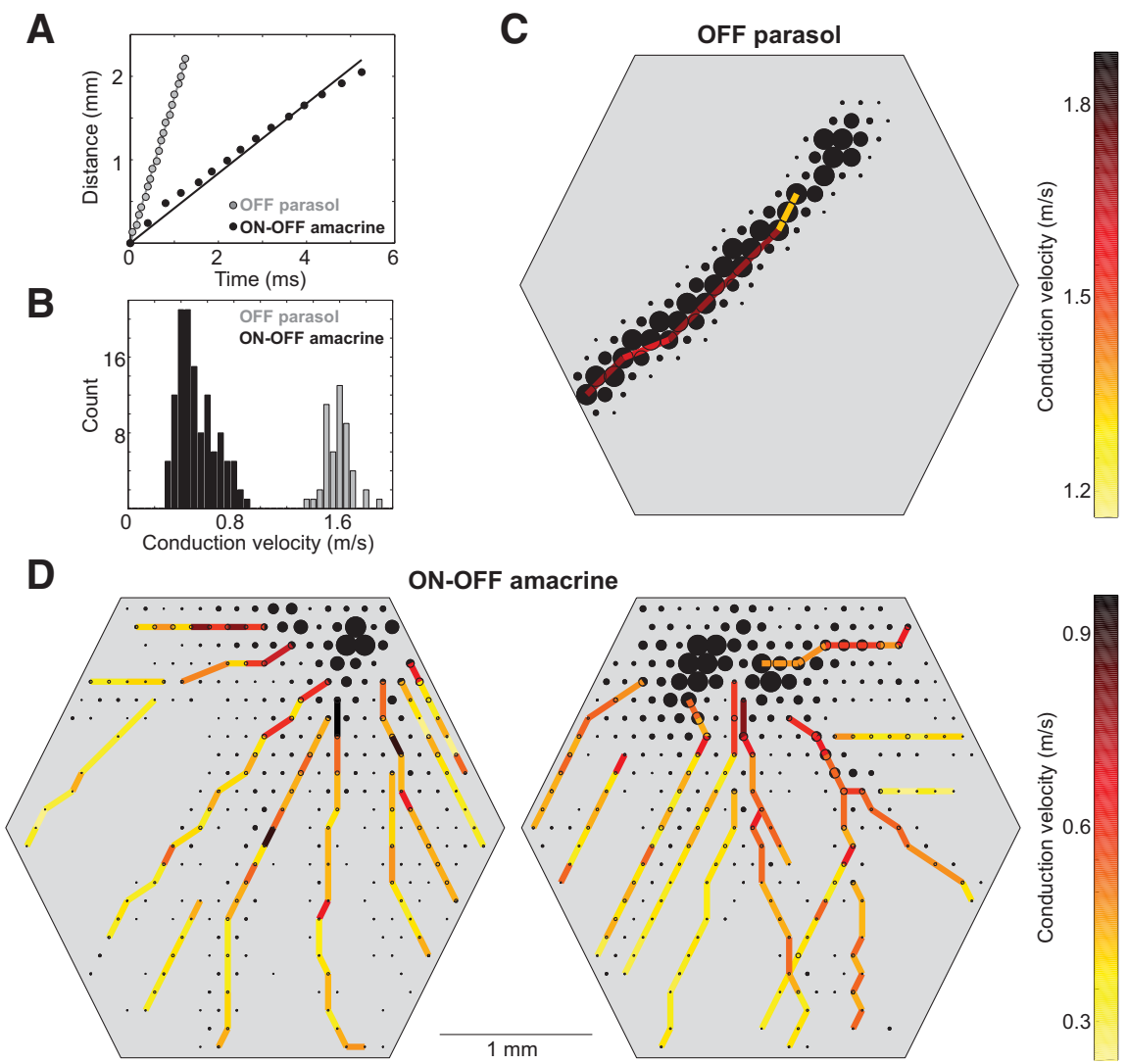

Figure 6. Propagation speed of axonal spikes. $A$, Times of axonal spikes obtained from specific electrodes (Fig. 1A, D) are shown along with the distance the spike traveled along the axon. Monotonic increase in spike time with distance is consistent with speeds, measured locally, are shown for an OFF parasol cell. Local propagation speeds were given by the ratio of distance

sitions relative to the image (Fig. 9C). By contrast, ON-OFF PACs with receptive fields at nearly the same locations as the OFF parasol cells fired infrequently and almost exclusively at image transitions (Fig. 9B). This observation suggests much higher stimulus selectivity in ON-OFF PACs. It also suggests a possible role in sensing changes in scene structure or position, and consequent inhibition of visual signals in their targets in the retinal circuitry. However, the firing of parasol cells at image transitions occurred, on average, 5-10 ms before the firing of ON-OFF PACs (data not shown). Such lags, combined with the relatively slow action potential propagation in ON-OFF PACs (Fig. 6), limits how rapidly PAC-mediated inhibition could act to suppress firing of RGCs (see Discussion).

\section{Additional polyaxonal amacrine cell type}

Although the ON-OFF PACs described above were the most frequently observed in the present recordings, in some cases other types of PACs were also recorded. One apparently distinct group of PACs was distinguished by $\mathrm{ON}$-dominated light responses with stereotyped kinetics (Fig. 10A,B); these cells were recorded simultaneously with ON-OFF PACs (Fig. 10C,D). Like ON-OFF PACs, the ON PACs exhibited axon conduction velocities 

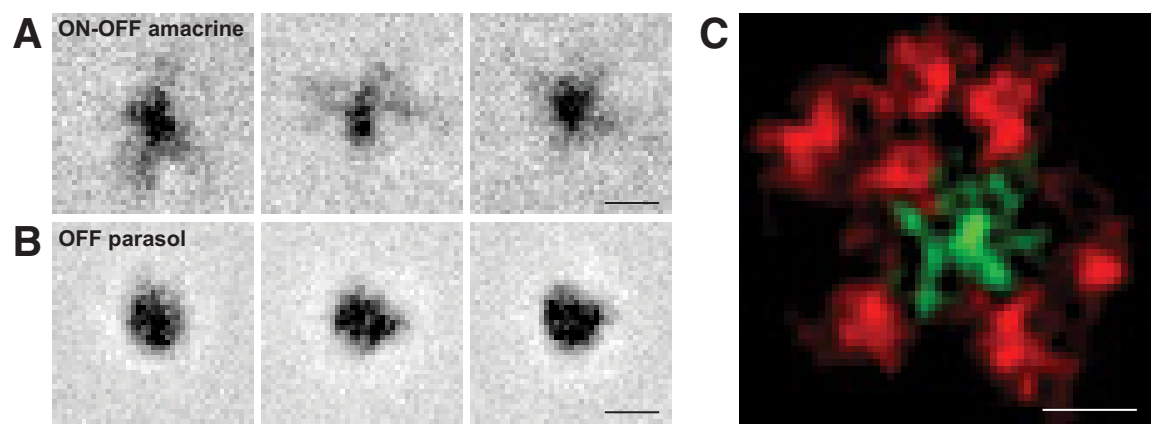

Figure 7. Fine structure in receptive fields of ON-OFF PACs. $A, B$, Receptive fields measured at high resolution are shown for three simultaneously recorded PACs and OFF parasol cells, revealing greater circular symmetry in parasol cells and irregular radial flares in the receptive fields of PACs. The display of the peak amplitude is saturated to improve the visibility of flares. Scale bar, 200 $\mu \mathrm{m}$. C, Smoothed, thresholded, and superimposed receptive fields of eight PACs suggests coordination in the receptive field microstructure of adjacent cells. Arbitrary coloring of the green cell for visual clarity. Scale bar, $200 \mu \mathrm{m}$.
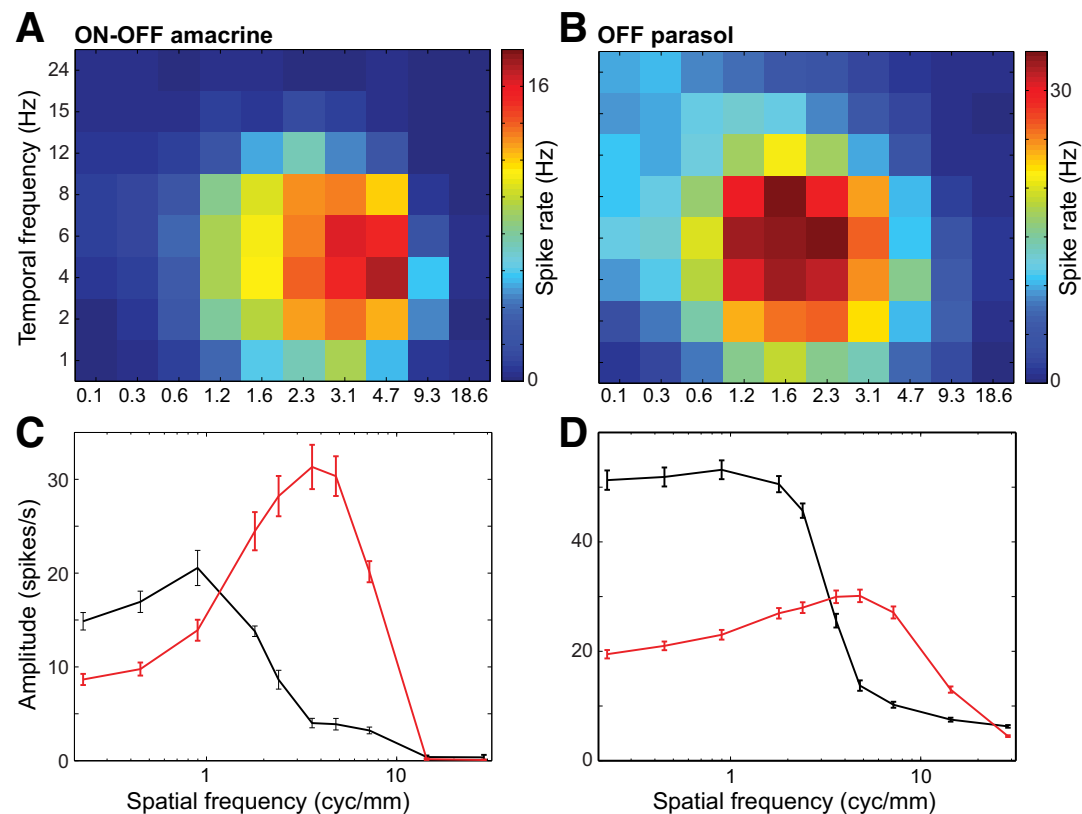

Figure 8. Selectivity and nonlinear spatial summation in response to grating stimuli. $\boldsymbol{A}$, The average spike rate of 10 simultaneously recorded ON-OFF PACs to drifting sinusoidal grating patterns ( $96 \%$ contrast) is shown as a heat map, as a function of the spatial and temporal frequency of the grating. $\boldsymbol{B}$, Same as $\boldsymbol{A}$, for 123 simultaneously recorded OFF parasol cells. Parasol cell responses were strongest at lower spatial frequencies than those of PACs. $C$, The average response amplitude of PACs in response to modulation of a stationary sinusoidal grating pattern is shown as a function of grating spatial frequency. The component of the response at the $F 1$ (black) is shown separately from the component at twice the fundamental frequency (i.e., the $F 2$, red). The error bars represent \pm 1 SEM $(n=5)$. D, Same as $C$, for simultaneously recorded OFF parasol cells $(n=52)$.

several-fold lower than those of parasol cells (data not shown). While the STA revealed a dominant ON response, the possibility of a weak OFF component also contributing to its responses cannot be excluded (Fig. 3A).

\section{Discussion}

Large-scale multielectrode recordings from isolated primate retinas revealed populations of PACs based on their characteristic radially propagating spikes. One PAC type, identified by stereotyped light response kinetics and mosaic organization, exhibited responses at light onset and offset, antagonistic receptive field surrounds, and strong homotypic electrical coupling. These cells also exhibited notably slow radial spike propagation, unusual receptive field microstructure, nonlinear spatial summation, and sparse and selective responses to structured visual stimuli.

\section{Anatomical identity of ON-OFF polyaxonal amacrine cells}

A number of PACs, of several distinct morphological types, have been described in various species (Dacey, 1988, 1989; Vaney et al., 1988; Famiglietti, 1992; Freed et al., 1996; Taylor, 1996; Stafford and Dacey, 1997; Völgyi et al., 2001; Wright and Vaney, 2004; Davenport et al., 2007), always characterized by small dendritic fields and long axonal processes spanning several millimeters of retina. As with RGCs, correspondences between specific cell types across species are somewhat unclear. However, in the primate retina, the A1 PAC type has been studied in more detail (Dacey, 1989; Stafford and Dacey, 1997; Davenport et al., 2007). Given their properties, the ON-OFF PACs described here could be the same population as the A1 cells. A1 cells exhibit fairly dense and symmetric radiating axonal processes, ON-OFF light responses to focal stimulation, antagonistic receptive field surrounds, homotypic tracer coupling, and density and dendritic field diameters approximately consistent with the $\mathrm{ON}-\mathrm{OFF}$ PACs.

It is perhaps surprising that nearly complete populations (Fig. 2A) of PACs were recorded with extracellular electrodes placed on the inner surface of the retina, given the variable soma positions of A1 cells in the inner nuclear layer, inner plexiform layer, and ganglion cell layer of the retina (Stafford and Dacey, 1997). A possible explanation is that variability in soma depth from animal to animal, or across the retina, could result in regions in which most or all A1 cells reside in the ganglion cell layer, and thus in occasional recordings of complete populations. This explanation would be consistent with the fact that, unlike ON and OFF parasol cells, large collections of ON-OFF PACs were observed only in a relatively small subset of recordings. On the other hand, given that the axons of PACs reside in the inner plexiform layer, the observation that axonal spikes from PACs can be reliably identified in the electrical image suggests that extracellular recordings may be able to pick up somatic spikes deeper in the retina as well. Note, however, that although the $\mathrm{A} 1$ cell is a reasonable candidate for the ON-OFF PACs reported here, the dearth of comprehensive information about the various types of PACs in the primate retina renders this anatomical correspondence uncertain.

\section{Mosaic organization}

A number of studies over several decades point to the conclusion that mosaic organization (i.e., regular tiling of the visual field) is a property of many, and perhaps all, cell types in the retina (Polyak, 1941; Wässle et al., 1983; Dacey, 1993; Vaney, 1994; Devries and Baylor, 1997; Haverkamp and Wässle, 2004; Field et 
al., 2007). In this light, it is not surprising that an amacrine cell type exhibits apparent mosaic organization. However, the evidence for mosaics is most obvious in photoreceptors, bipolar cells, and ganglion cells, each of which must transmit a complete representation of the visual field to the next layer of processing. It seems possible that PACs, which instead play a role in feedback modulation of visual signals, with sparsely distributed outputs over very large areas of retina, could exhibit a less regular and complete sampling of visual space. However, the ON-OFF PAC mosaics observed here were comparable to those of ON and OFF parasol cells (Fig. 2), two of the major visual pathways to the primate brain.

\section{Electrical coupling}

The strong electrical coupling between neighboring ON-OFF PACs appears to be mediated by gap junctions (Fig. 5) and may provide clues to PAC function. Although homotypic gap junction coupling is widespread in the retinal circuitry (Völgyi et al., 2009), it appears to play a relatively minor role in the output cells of the primate retina. Specifically, among the six ganglion cell types for which comparable information about coupling exists (ON and OFF parasol, ON and OFF midget, small bistratified, and upsilon cells ( $\sim 75 \%$ of all ganglion cells; Dacey, 2004), only the ON parasol cells exhibit obvious electrical coupling (Greschner et al., 2011). Furthermore, the coupling between ON-OFF PACs is much stronger than the coupling between ON parasol cells. Also, the axonal processes for each ON-OFF PAC spread nonuniformly and far beyond the area over which they respond to light (Fig. 4). Thus, strong electrical coupling between ON-OFF PACs could produce a more spatially uniform modulation of visual signals than would otherwise occur (see below).

\section{Selective and sparse visual signals}

The sparse response of ON-OFF PACs to stimulation with moving natural scenes also provides clues to their function. A variety of PACs have been described in several species that modulate RGC firing in response to spatially extended stimuli in regions of

A Stimulus

OFF parasol static or moved slowly.
B ON-OFF amacrine

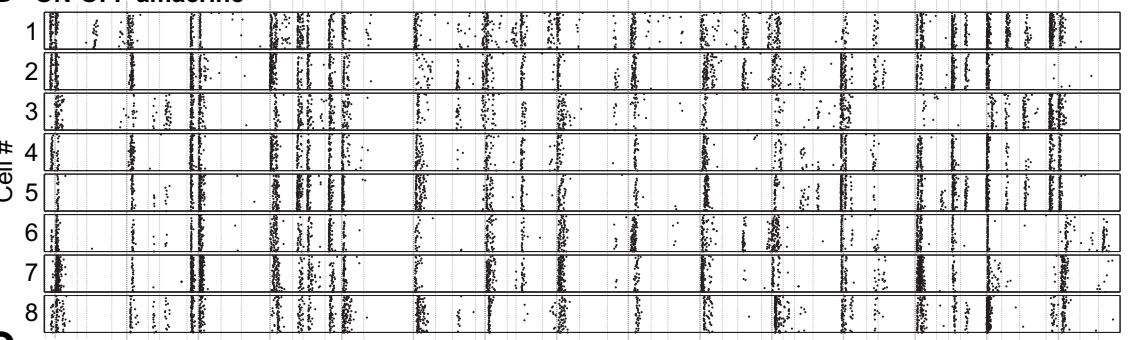

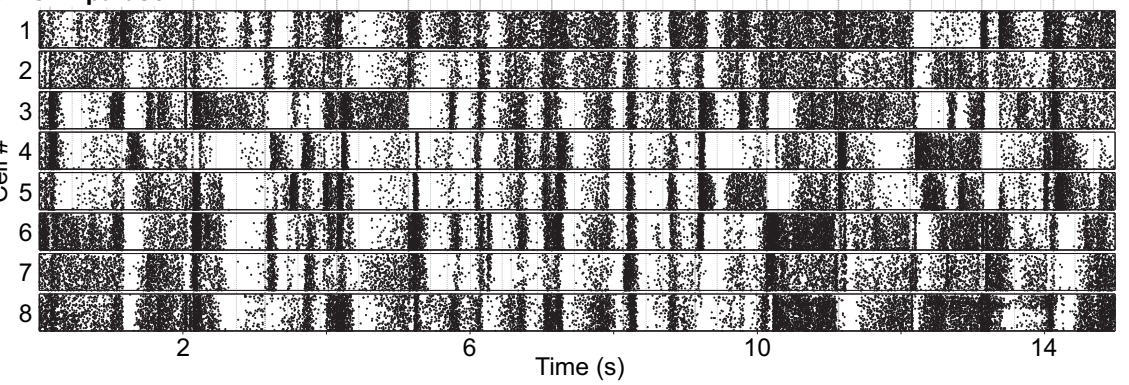

Figure 9. Responses of PACs and parasol cells to moving natural scenes. A, Stimulus composed of monochrome images of natural scenes was moved over the retina with a trajectory determined from recordings of the eye position of a fixating macaque monkey, with superimposed simulated saccades (see Materials and Methods). Red and black traces show the horizontal and vertical components of movement respectively over time, with discrete simulated saccades (abrupt horizontal deflections indicated by periodic pulses in the red trace) interspersed with slower and smaller fixational eye movements. For visual guidance, vertical lines indicate saccades above an arbitrary amplitude. $\boldsymbol{B}$, Responses of eight PACs simultaneously recorded are shown in raster format; each tick represents a single spike, and each row represents a single presentation of the repeated stimulus. Strong responses occurred primarily at large image movements, mostly saccades. C, Responses of eight OFF parasol cells, each of which exhibits substantial receptive field overlap with the correspondingly numbered PAC in $\boldsymbol{B}$, recorded simultaneously with the data from $\boldsymbol{B}$. Parasol cells also exhibited strong responses at image transitions, but spikes also occurred at times when the image was

the retina far from the RGC receptive field center, in some cases with a high spatial resolution that suggests strong inputs from nonlinear subunits (presumably, bipolar cells; Shapley and Victor, 1979; Demb et al., 2001). One class of PACs of this kind in salamander and rabbit retinas suppresses RGC responses to ongoing full-field motion arising from eye movements (Olveczky et al., 2003; Baccus et al., 2008).

Although the ON-OFF PACs reported here exhibited apparent nonlinear subunit properties (Fig. 8), they fired only at sharp transitions in the visual scene rather than continuously during slower movement (Fig. 9). Assuming that these ON-OFF PACs provide inhibitory input to other retinal neurons (Roska and Werblin, 2003), it seems that their selective properties could sup-
A ON amacrine

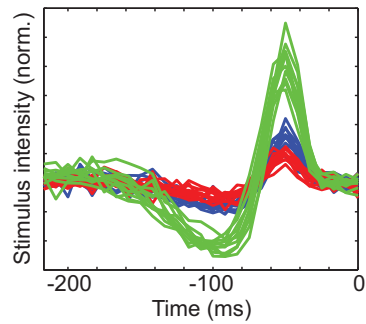

B

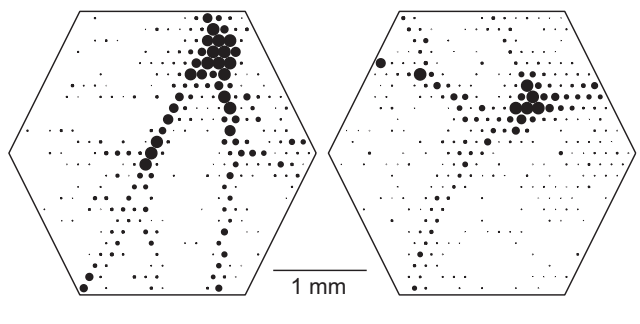

C ON-OFF amacrine

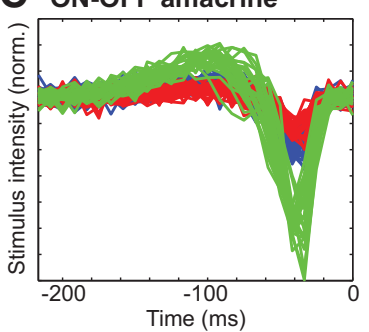

D

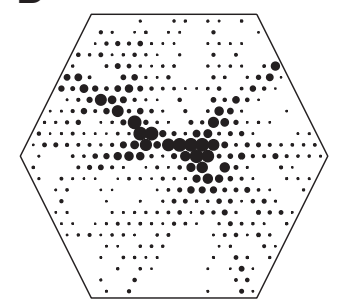

Figure 10. ON dominated polyaxonal amacrine cells. $\boldsymbol{A}$, Time course of reverse correlation superimposed for ON PACS, as in Figure 2D-F. $\boldsymbol{B}$, Electrical images of two $0 \mathrm{~N} P A C S$, as in Figure $1 C$. $\boldsymbol{C}, \boldsymbol{D}$, Time courses and a single electrical image of ON-OFF PACs recorded simultaneously. 
press retinal signals at times when visual information is changing too rapidly or over such a large area that the incident visual information is unlikely to be useful for behavior. The strong electrical coupling could further enforce the condition that firing in the population of ON-OFF PACs can only have a large influence during global image motion. Thus, these cells could potentially mediate functions such as suppression of visual processing during global image translation produced by saccadic eye movements (Roska and Werblin, 2003). However, the relatively slow action potential propagation indicates that these effects are unlikely to occur on the millisecond time scale.

Despite these clues, the role of the ON-OFF PACs in visual processing remains unclear. Many different instances of response suppression in RGCs from areas far from the classical receptive field have been reported (McIlwain, 1964; Levick et al., 1965; Ikeda and Wright, 1972; Werblin, 1972; Krüger and Fischer, 1973; Schwartz, 1973; Cleland and Levick, 1974; Caldwell and Daw, 1978; Enroth-Cugell and Jakiela, 1980; Watanabe and Tasaki, 1980; Taylor, 1999; Passaglia et al., 2001; Roska and Werblin, 2003; Solomon et al., 2006; Zaghloul et al., 2007), presumably reflecting the action of multiple amacrine cell types modulating the activity of multiple ganglion cell types. Examination of $\mathrm{ON}-$ OFF PAC firing did not reveal any obvious relationship to visual signals in simultaneously recorded parasol and midget cells. Thus, this PAC population may not play a substantial role in modulating visual signals in the dominant visual pathways of primates, at least in the conditions examined. It appears that several distinct populations of PACs, each with stereotyped response properties and spatial arrangement, modulate visual signaling in the primate retina. Given the number of RGC and PAC types, further work is needed to study this complex set of circuits.

\section{References}

Ala-Laurila P, Greschner M, Chichilnisky EJ, Rieke F (2011) Cone photoreceptor contributions to noise and correlations in the retinal output. Nat Neurosci 14:1309-1316. CrossRef Medline

Baccus SA, Olveczky BP, Manu M, Meister M (2008) A retinal circuit that computes object motion. J Neurosci 28:6807-6817. CrossRef Medline

Caldwell JH, Daw NW (1978) New properties of rabbit retinal ganglion cells. J Physiol 276:257-276. Medline

Chichilnisky EJ (2001) A simple white noise analysis of neuronal light responses. Network 12:199-213. CrossRef Medline

Chichilnisky EJ, Baylor DA (1999) Receptive-field microstructure of blueyellow ganglion cells in primate retina. Nat Neurosci 2:889-893. CrossRef Medline

Chichilnisky EJ, Kalmar RS (2002) Functional asymmetries in ON and OFF ganglion cells of primate retina. J Neurosci 22:2737-2747. Medline

Cleland BG, Levick WR (1974) Brisk and sluggish concentrically organized ganglion cells in the cat's retina. J Physiol 240:421-456. Medline

Crook JD, Peterson BB, Packer OS, Robinson FR, Troy JB, Dacey DM (2008) $\mathrm{Y}$-cell receptive field and collicular projection of parasol ganglion cells in macaque monkey retina. J Neurosci 28:11277-11291. CrossRef Medline

Dacey DM (1988) Dopamine-accumulating retinal neurons revealed by in vitro fluorescence display a unique morphology. Science 240:1196-1198. CrossRef Medline

Dacey DM (1989) Axon-bearing amacrine cells of the macaque monkey retina. J Comp Neurol 284:275-293. CrossRef Medline

Dacey DM (1993) The mosaic of midget ganglion cells in the human retina. J Neurosci 13:5334-5355. Medline

Dacey DM, Brace S (1992) A coupled network for parasol but not midget ganglion cells in the primate retina. Vis Neurosci 9:279-290. CrossRef Medline

Dacey DM (2004) Origins of perception: retinal ganglion cell diversity and the creation of parallel visual pathways. In: The cognitive neurosciences (Gazzaniga MS, eds), pp 281-301. Cambridge, MA: MIT.

Davenport CM, Detwiler PB, Dacey DM (2007) Functional polarity of dendrites and axons of primate A1 amacrine cells. Vis Neurosci 24:449-457. CrossRef Medline
Demb JB, Zaghloul K, Haarsma L, Sterling P (2001) Bipolar cells contribute to nonlinear spatial summation in the brisk-transient $(\mathrm{Y})$ ganglion cell in mammalian retina. J Neurosci 21:7447-7454. Medline

DeVries SH (1999) Correlated firing in rabbit retinal ganglion cells. J Neurophysiol 81:908-920. Medline

Devries SH, Baylor DA (1997) Mosaic arrangement of ganglion cell receptive fields in rabbit retina. J Neurophysiol 78:2048-2060. Medline

Enroth-Cugell C, Jakiela HG (1980) Suppression of cat retinal ganglion cell responses by moving patterns. J Physiol 302:49-72. Medline

Famiglietti EV (1992) Polyaxonal amacrine cells of rabbit retina: morphology and stratification of PA1 cells. J Comp Neurol 316:391-405. CrossRef Medline

Field GD, Chichilnisky EJ (2007) Information processing in the primate retina: circuitry and coding. Annu Rev Neurosci 30:1-30. CrossRef Medline

Field GD, Sher A, Gauthier JL, Greschner M, Shlens J, Litke AM, Chichilnisky EJ (2007) Spatial properties and functional organization of small bistratified ganglion cells in primate retina. J Neurosci 27:13261-13272. CrossRef Medline

Frechette ES, Sher A, Grivich MI, Petrusca D, Litke AM, Chichilnisky EJ (2005) Fidelity of the ensemble code for visual motion in primate retina. J Neurophysiol 94:119-135. CrossRef Medline

Freed MA, Pflug R, Kolb H, Nelson R (1996) ON-OFF amacrine cells in cat retina. J Comp Neurol 364:556-566. CrossRef Medline

Gauthier JL, Field GD, Sher A, Greschner M, Shlens J, Litke AM, Chichilnisky EJ (2009) Receptive fields in primate retina are coordinated to sample visual space more uniformly. PLoS Biol 7:e63. CrossRef Medline

Gollisch T, Meister M (2010) Eye smarter than scientists believed: neural computations in circuits of the retina. Neuron 65:150-164. CrossRef Medline

Greschner M, Shlens J, Bakolitsa C, Field GD, Gauthier JL, Jepson LH, Sher A, Litke AM, Chichilnisky EJ (2011) Correlated firing among major ganglion cell types in primate retina. J Physiol 589:75-86. CrossRef Medline

Haverkamp S, Wässle H (2004) Characterization of an amacrine cell type of the mammalian retina immunoreactive for vesicular glutamate transporter 3. J Comp Neurol 468:251-263. CrossRef Medline

Hochstein S, Shapley RM (1976) Quantitative analysis of retinal ganglion cell classifications. J Physiol 262:237-264. Medline

Ikeda H, Wright MJ (1972) Functional organization of the periphery effect in retinal ganglion cells. Vision Res 12:1857-1879. CrossRef Medline

Krüger J, Fischer B (1973) Strong periphery effect in cat retinal ganglion cells. Excitatory responses in ON- and OFF- center neurones to single grid displacements. Exp Brain Res 18:316-318. Medline

Levick WR, Oyster CW, Davis DL (1965) Evidence that Mcllwain's periphery effect is not a stray light artifact. J Neurophysiol 28:555-559. Medline

Litke AM, Bezayiff N, Chichilnisky EJ, Cunningham W, Dabrowski W, Grillo AA, Grivich M, Grybos P, Hottowy P, Kachiguine S (2004) What does the eye tell the brain? Development of a system for the large-scale recording of retinal output activity. IEEE Trans Nucl Sci 51:1434-1440. CrossRef

Mariani AP (1990) Amacrine cells of the rhesus monkey retina. J Comp Neurol 301:382-400. CrossRef Medline

Masland RH (2001) The fundamental plan of the retina. Nat Neurosci 4:877-886. CrossRef Medline

Masland RH (2012) The neuronal organization of the retina. Neuron 76: 266-280. CrossRef Medline

Mastronarde DN (1983a) Correlated firing of cat retinal ganglion cells. I. Spontaneously active inputs to X- and Y-cells. J Neurophysiol 49:303324. Medline

Mastronarde DN (1983b) Interactions between ganglion cells in cat retina. J Neurophysiol 49:350-365. Medline

McIlwain JT (1964) Receptive fields of optic tract axons and lateral geniculate cells: peripheral extent and barbiturate sensitivity. J Neurophysiol 27:1154-1173. Medline

Olveczky BP, Baccus SA, Meister M (2003) Segregation of object and background motion in the retina. Nature 423:401-408. CrossRef Medline

Passaglia CL, Enroth-Cugell C, Troy JB (2001) Effects of remote stimulation on the mean firing rate of cat retinal ganglion cells. J Neurosci 21:57945803. Medline

Perkel DH, Gerstein GL, Moore GP (1967) Neuronal spike trains and stochastic point processes. II. Simultaneous spike trains. Biophys J 7:419-440. CrossRef Medline 
Petrusca D, Grivich MI, Sher A, Field GD, Gauthier JL, Greschner M, Shlens J, Chichilnisky EJ, Litke AM (2007) Identification and characterization of a Y-like primate retinal ganglion cell type. J Neurosci 27:11019-11027. CrossRef Medline

Polyak SL (1941) The retina. Chicago: University of Chicago.

Rodieck RW (1998) The first steps in seeing. Sunderland, MA: Sinauer.

Roska B, Werblin F (2003) Rapid global shifts in natural scenes block spiking in specific ganglion cell types. Nat Neurosci 6:600-608. CrossRef Medline

Schwartz EA (1973) Organization of on-off cells in the retina of the turtle. J Physiol 230:1-14. Medline

Shapley RM, Victor JD (1979) Nonlinear spatial summation and the contrast gain control of cat retinal ganglion cells. J Physiol 290:141-161. Medline

Shlens J, Field GD, Gauthier JL, Grivich MI, Petrusca D, Sher A, Litke AM, Chichilnisky EJ (2006) The structure of multi-neuron firing patterns in primate retina. J Neurosci 26:8254-8266. CrossRef Medline

Shlens J, Rieke F, Chichilnisky E (2008) Synchronized firing in the retina. Curr Opin Neurobiol 18:396-402. CrossRef Medline

Solomon SG, Lee BB, Sun H (2006) Suppressive surrounds and contrast gain in magnocellular-pathway retinal ganglion cells of macaque. J Neurosci 26:8715-8726. CrossRef Medline

Stafford DK, Dacey DM (1997) Physiology of the Al amacrine: a spiking, axon-bearing interneuron of the macaque monkey retina. Vis Neurosci 14:507-522. CrossRef Medline

Taylor WR (1996) Response properties of long-range axon-bearing amacrine cells in the dark-adapted rabbit retina. Vis Neurosci 13:599-604. CrossRef Medline

Taylor WR (1999) TTX attenuates surround inhibition in rabbit retinal ganglion cells. Vis Neurosci 16:285-290. Medline
Trong PK, Rieke F (2008) Origin of correlated activity between parasol retinal ganglion cells. Nat Neurosci 11:1343-1351. CrossRef Medline

van Hateren JH, van der Schaaf A (1998) Independent component filters of natural images compared with simple cells in primary visual cortex. Proc Biol Sci 265:359-366. CrossRef Medline

Vaney DI (1994) Territorial organization of direction-selective ganglion cells in rabbit retina. J Neurosci 14:6301-6316. Medline

Vaney DI, Peichl L, Boycott BB (1988) Neurofibrillar long-range amacrine cells in mammalian retinae. Proc R Soc Lond B Biol Sci 235:203-219. CrossRef Medline

Völgyi B, Xin D, Amarillo Y, Bloomfield SA (2001) Morphology and physiology of the polyaxonal amacrine cells in the rabbit retina. J Comp Neurol 440:109-125. CrossRef Medline

Völgyi B, Chheda S, Bloomfield SA (2009) Tracer coupling patterns of the ganglion cell subtypes in the mouse retina. J Comp Neurol 512:664-687. CrossRef Medline

Wässle H, Peichl L, Boycott BB (1981) Dendritic territories of cat retinal ganglion cells. Nature 292:344-345. CrossRef Medline

Wässle H, Peichl L, Boycott BB (1983) Mosaics and territories of cat retinal ganglion cells. Prog Brain Res 58:183-190. CrossRef Medline

Watanabe J, Tasaki K (1980) Shift-effect in the rabbit retinal ganglion cells. Brain Res 181:198-201. CrossRef Medline

Werblin FS (1972) Lateral interactions at inner plexiform layer of vertebrate retina: antagonistic responses to change. Science 175:1008-1010. CrossRef Medline

Wright LL, Vaney DI (2004) The type 1 polyaxonal amacrine cells of the rabbit retina: a tracer-coupling study. Vis Neurosci 21:145-155. CrossRef Medline

Zaghloul KA, Manookin MB, Borghuis BG, Boahen K, Demb JB (2007) Functional circuitry for peripheral suppression in Mammalian Y-type retinal ganglion cells. J Neurophysiol 97:4327-4340. CrossRef Medline 